\title{
ENSINO DE PROJETO HABITANDO OS TERRITÓRIOS HABITADOS: DERIVA E CARTOGRAFIA
}

ENSEÑANZA DEL PROYECTO HABITANDO EL TERRITORIO HABITADO: DERIVA Y CARTOGRAFÍA

PROJECT TEACHING INHABITING INHABITED TERRITORIES: DERIVE AND CARTOGRAPHY

HIRAO, HELIO.

Doutor, Universidade Estadual Paulista, UNESP Presidente Prudente, e-mail: hélio.hirao@unesp.br

RAMOS, ALFREDO Z. N.

Doutorando, UNESP Presidente Prudente, e-mail: aznramos@gmail.com

NUNES, JOÃO O. R.

Livre Docente, UNESP Presidente Prudente, e-mail: joao.o.nunes@unesp.br

\section{RESUMO}

Trata-se de uma experimentação de procedimento metodológico do ensino de projeto arquitetônico realizada no segundo ano do curso de Arquitetura e Urbanismo da UNESP Campus de Presidente Prudente (2019), a partir da prática espacial de derivas e cartografias de forças e afetos, potencializando uma interlocução transversal com a disciplina de geomorfologia. A experimentação retarda o encontro com as analogias tipológicas para conceber as formas arquitetônicas, realizando uma imersão na tessitura das relações de afetos que atravessam os corpos (humano e arquitetônico). Afasta, assim, dos procedimentos lineares e padronizados através da identificação e reconhecimento dos territórios que habitam o espaço. Desse modo, a proposta de elaboração de um centro comunitário em um bairro periférico de Presidente Prudente, SP, não buscou resolver seus problemas, mas ressingularizar práticas e afetos existentes, para potencializar o sentimento de pertencimento dos sujeitos com seu espaço, valorizando a transitoriedade da intervenção projetual de uma realidade em constante movimento e transformação, como também, projetando espaços indeterminados e flexíveis a serem determinados pelos sujeitos dos espaços.

PALAVRAS-CHAVE: deriva; cartografia; projeto de arquitetura.

\section{RESUMEN}

Se trata de una experimentación del procedimiento metodológico de enseñanza del proyecto arquitectónico realizado en el segundo año de la carrera de Arquitectura y Urbanismo de la UNESP Campus de Presidente Prudente (2019), basado en la práctica espacial de derivas y cartografías de fuerzas y afectos, potenciando un diálogo transversal con la disciplina de la geomorfología. La experimentación retrasa el encuentro con analogías tipológicas para concebir formas arquitectónicas, sumergiéndose en el tejido de las relaciones afectivas que impregnan los cuerpos (humanos y arquitectónicos). Así, se aleja de los procedimientos lineales y estandarizados mediante la identificación y reconocimiento de los territorios que habitan el espacio. Así, la propuesta de desarrollar un centro comunitario en un barrio periférico de Presidente Prudente, SP, no buscaba resolver sus problemas, sino re-singularizar las prácticas y afectos existentes, para potenciar el sentimiento de pertenencia de los sujetos con su espacio, valorar la fugacidad de la intervención del proyecto de una realidad en constante movimiento y transformación, asi como proyectar espacios indeterminados y flexibles a ser determinados por los sujetos de los espacios.

PALABRAS CLAVES: deriva; cartografía; proyecto arquitectónico.

\section{ABSTRACT}

This is a methodological experimentation of an architecture teaching procedure teaching carried out in the second year of the Architecture and Urbanism course at UNESP Campus de Presidente Prudente (2019), based on derive spatial practice and cartographies of forces and affections, enhancing a transversal dialogue with the geomorphology discipline. Experimentation delays the encounter with typological analogies in order to conceive architectural forms, immersing themselves in affective relationships fabric that permeate bodies (human and architectural). It thus distances itself from linear and standardized procedures through identification and recognition of the territories that inhabit the space. Therefore, the proposal to develop a community center in Presidente Prudente, SP peripheral neighborhood, did not seek to solve its problems, but to re-singularize existing practices and affections, to enhance the feeling of belonging subjects with their space, valuing the transience of the design intervention of a reality in constant movement and transformation, as well as designing indeterminate spaces to be determined by the subjects of the spaces.

KEYWORDS: derive; cartography; architectural design. 


\section{INTRODUÇÃO}

O artigo relata e provoca para o debate, a prática do ensino do projeto arquitetônico para os primeiros anos do curso de Arquitetura e Urbanismo. A experimentação foi desenvolvida com os alunos da Universidade Estadual Paulista "Júlio de Mesquita Filho" - UNESP, Campus de Presidente Prudente, SP, no segundo semestre de 2019.

Ativa conexões entre a prática projetual e o pensamento arquitetônico, em busca de alternativas de procedimentos metodológicos para o ensino projetual considerando, também, a potencialidade da interlocução interdisciplinar, nessa experimentação, entre Projeto de Arquitetura I e Geomorfologia.

O ensino de projeto, nas escolas de arquitetura, identifica-se, ainda com a persistência hegemônica de utilizar analogias formais com modelos icônicos como referência tipológica para conceber novos projetos, o que estimula uma produção padronizada, estandardizada e repetitiva.

Da forma tradicional, o aprendiz de arquiteto simplesmente reproduz formas estéticas desvinculadas das intensidades das múltiplas conexões das relações entre os corpos humanos e ambiências arquitetônicas que conformam territórios habitados.

O reconhecimento do projeto arquitetônico como forma, que expressa seu conteúdo de práticas socioespaciais existentes compondo como ressingularização dos múltiplos, heterogêneos e diversos territórios habitados, sem hierarquias, simultâneos, conflitantes ou coexistentes, apreendidos como rizoma (DELEUZE e GUATTARI, 2019) e trabalhadas como potências criativas do novo agenciamento de ativações de afetos que atravessam os corpos, as ambiências e atmosferas do espaço.

Desenvolveu assim, o projeto arquitetônico de um centro comunitário para o bairro periférico da cidade de Presidente Prudente, SP, Jardim João Domingos (Figura 1).

A interlocução interdisciplinar foi colocada naturalmente nas atividades de campo e de atelier, consideradas como partes simultâneas em um processo projetual, inclusive na avaliação final das disciplinas.

\footnotetext{
Figura 1: O Bairro João Domingos e o centro da cidade de Presidente Prudente.
}

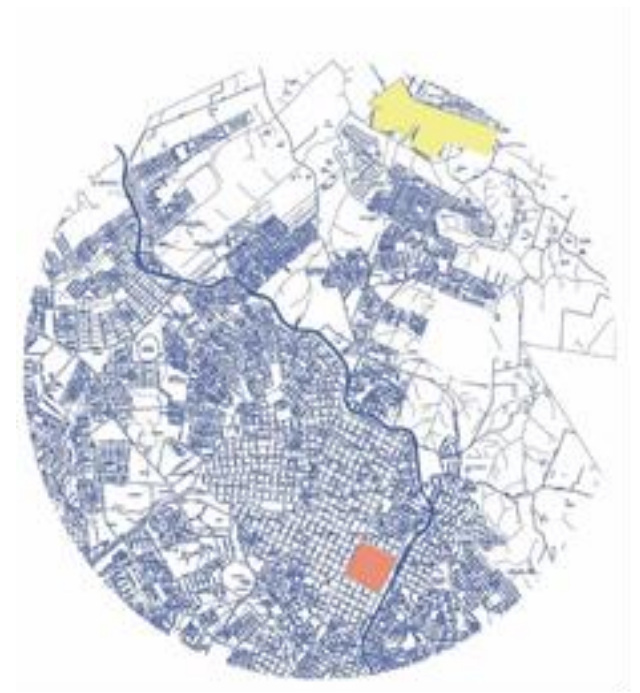

Fonte: Arquivo do Grupo de Pesquisa "Projeto, Arquitetura e Cidade"

Para tanto, a ideia de elaborar um centro comunitário para o bairro não partiu de um modelo já preexistente, foi construída nas práticas das derivas (DEBORD,1958; CARERI, 2013) realizadas e, na cognição das cartografias (DELEUZE, GUATTARI, 2019 ) que expressam graficamente a apreensão das presenças, rastros e pegadas das múltiplas práticas espaciais existentes. Conceberam, assim, o espaço institucional engendrando intervenções, habitando a tessitura de afetos dos territórios habitados.

Desse modo, imersos na ambiência e atmosfera do João Domingos, em um processo simultâneo, não linear, da experimentação e intervenção, os alunos elaboraram um projeto de um centro comunitário em uma ambiência em movimento e em constante transformação, sem a pretensão de solucionar os problemas do bairro, mas de intervir para potencializar as forças e afetos existentes possibilitando considerar as pessoas como sujeitas do espaço ao ativar os territórios existenciais além dos funcionais. 
Ao tornar o aluno, protagonista do processo projetual, não reproduzindo ou adequando modelos já existentes, o fez compartilhar o habitar com a ambiência e atmosfera existente, em constante transformação, relatando o espaço de dentro da experimentação espacial, promovendo a ativação das relações subjetivas entre corpo (sujeito), objeto (arquitetura) e território (geografia).

Assim, a produção projetual surpreende pelas qualidades da forma, não como cenários idealizados a serem contemplados, mas como expressões do conteúdo do contexto experimentado nas práticas de apreensão.

Em 2021, os projetos foram classificados para a exposição no $27^{\circ}$ Congresso Mundial de Arquitetura UIA2021RIO/ O novo rumo da Arquitetura expresso em práticas acadêmicas e projetos de estudantes.

\section{PRÁTICA ESPACIAL E PENSAMENTO ARQUITETÔNICO}

O contexto contemporâneo da prática e pensamento da arquitetura ainda convive com as questões consequentes da crise da modernidade (LIMA, 2002), onde o enfrentamento crítico das questões sociais e estéticas caminhou para um projeto idealizado e utópico distante da realidade existente.

Assim como, temos o reconhecimento da arquitetura contemporânea como operadora de visibilidades, consagrado na saturação do espaço, primordialmente focada nas funções úteis e inúteis, promovendo a perda da ilusão e sedução, o que remete para a necessidade de restituição de suas relações sensíveis socioespaciais expressando os valores de seus usuários (BAUDRILARD, 1999).

Por outro lado, a experiência espacial coloca a imaginação, as vivências e as intenções dos criadores em sintonia com as experiências, as necessidades, os desejos e as aspirações dos sujeitos do espaço (MONTANER, 2016).

O desafio da arquitetura como disciplina e prática no atual contexto econômico, social e cultural, estimula o movimento de pensar o processo projetual. A forma da ambiência precisa expressar o conteúdo e o contexto de suas diversas multiplicidades e singularidades socioespaciais. Colocam-se, assim, a premência de ressingularizar os imaginários sociais com as práticas espaciais vivenciadas no presente e no cotidiano, que conduza a conexão entre o passado e a possibilidade de projeções do futuro (LIMA, 2002).

Nesse sentido, não cabe, o procedimento metodológico projetual dos modelos de projetos, reprodutoras de tipologias consagradas, através da adoção arbitrária de princípios que desprezam as situações concretas existentes, é relevante compreender que "a arquitetura não é o conhecimento da forma, mas sim, uma forma de conhecimento" (GUIZZO, 2019).

Do mesmo modo, o projeto arquitetônico não nasce de uma abstração de uma inspiração divina ou de um impulso genial do arquiteto, mas de um agenciamento de múltiplos fatores heterogêneos, sem hierarquizar, tecendo, compondo e ativando linhas funcionais e existenciais da rede de conexões entre corpo, objeto e território, considerando as coexistências e conflitos existentes.

Contrário ao procedimento que inicia com desenvolvimento de um programa de atividades adotando a máxima modernista de "a forma segue a função", adotou-se, a perspectiva adotada por Tshummi (2005), onde "a forma segue o conceito".

A construção do conceito considera a tessitura da rede de relações do conteúdo e o do contexto. Esse contexto é histórico, geográfico, cultural, político ou econômico que situa o projeto no território, por outro lado, o conteúdo expressa as diversas e heterogêneas práticas socioespaciais que conectam os corpos através de intensidades de forças e afetos entre sujeitos, objetos e territórios.

Além da apreensão, reconhecimento e ativação das práticas socioespaciais, há que se entender a manifestação, do que Deleuze e Guattari (1972) denominam de "máquina dos desejos", manifestando-se dentro das condicionantes externas citadas anteriormente. "A essência da máquina está ligada a procedimentos que desterritorializam seus elementos, funções e relações de alteridade".

O estudante, neste exercício prático, tende a exercer também considerações e vontades enraizadas dentro de seu repertório adquirido, porém a prática, ao se atentar para as forças e afetos nos seus territórios, reprograma a máquina em direção a novas condicionantes.

Peter Eisenman (2015, p. 282), por exemplo, expressa a relevância deste exercício e revela que a verificação empírica de resultados leva a situações de evolução ao arquiteto para pensar como o espaço é experimentado: construir para entender os resultados. $O$ construir pode ser entendido também pelo uso da prática existente e seus resultados prévios, que delimitam os parâmetros para a intervenção e proposta projetual dos alunos. 
Neste enquadramento, o ensino de projeto, além de olhar para a experimentação espacial, busca tornar o aluno protagonista do ensino de projeto, compartilhando e construindo seu desenvolvimento com os professores.

Desse modo, verifica-se que a arquitetura está enraizada em nossas experiências de estar no mundo através de sua vida de experiências e de suas presenças emotivas, confronta e internaliza esses espaços e as ambiências como experiências existenciais corporificadas (PALLASMAA, 2018 ). Esse processo não é linear, mas multiplamente entrelaçado e, desse modo, a qualidade arquitetônica relaciona-se, quando se é tocada, ou afetada por ela. Então as conexões dos múltiplos territórios relacionando corpo humano com ambiência traz a presença uma atmosfera (ZUMTHOR, 2009) que afeta e é afetada pelos sujeitos.

\section{DERIVA E CARTOGRAFIA}

Esta perspectiva do ensino de projeto de arquitetura vem sendo experienciada há quatro anos no curso de arquitetura e urbanismo da UNESP de Presidente Prudente.

As tessituras das conexões interdisciplinares da arquitetura e geomorfologia se intensificaram simultaneamente com a compreensão do projeto como movimento do pensamento através da adoção do procedimento metodológico de apreensão e cognição da realidade espacial da cidade utilizando a deriva e da cartografia de forças e afetos do ambiente experimentado.

Deste modo, a partir da prática da deriva e experimentação da cartografia desenvolveu um processo de apreensão, cognição e reconhecimento do espaço através de cartografias com expressões visuais gráficas.

Assumiu a possibilidade de apreensão do espaço experimentado, com a prática cartográfica (DELEUZE, GUATTARI, 12019) através de mapas móveis do espaço vivenciado constituindo-se em uma experimentação ancorada no real. E, esse mapa da cidade é atualizado através prática do espaço, agora apropriada e modificada pelos seus habitantes (JACQUES, 2003). Reconheceram as micros-práticas do lugar, as diversas apropriações como micros-resistências ou táticas de resistências dos praticantes deste espaço (CERTEAU, 1998), por vezes despercebidas ao olhar pragmático e especulativo da dinâmica cotidiana da cidade produtiva.

Compreenderam as cartografias como mapas móveis que procuram descrever as experiências dos espaços de forma rizomática (DELEUZE, GUATARRI, 2019), expressando graficamente as redes de conexões dos afetos, das práticas socioculturais e de uma configuração de elementos, forças, ou linhas que atuam simultaneamente no espaço.

Ao lado do plano das formas, objetos ou sujeitos coexiste um plano coletivo de forças que os produzem, em um processo constante de transformação, considerando os efeitos da subjetivação (ESCÓSSIA; TEDESCO, 2015).

Como as formas são resultantes das conexões e intensidades das forças e correspondem a coagulações, a conglomerados de vetores mapeia esse enquadramento de forças visando a cognição destas potências em expressões gráficas desses fluxos de intensidades e das singularidades dos espaços.

Desse modo, os alunos divididos em grupos foram ao campo sem conhecimento prévio do espaço para praticar a deriva experimentando seus espaços e produzindo cartografias com expressões gráficas, relatando a cidade funcional e subjetiva vivenciada (Figura 2).

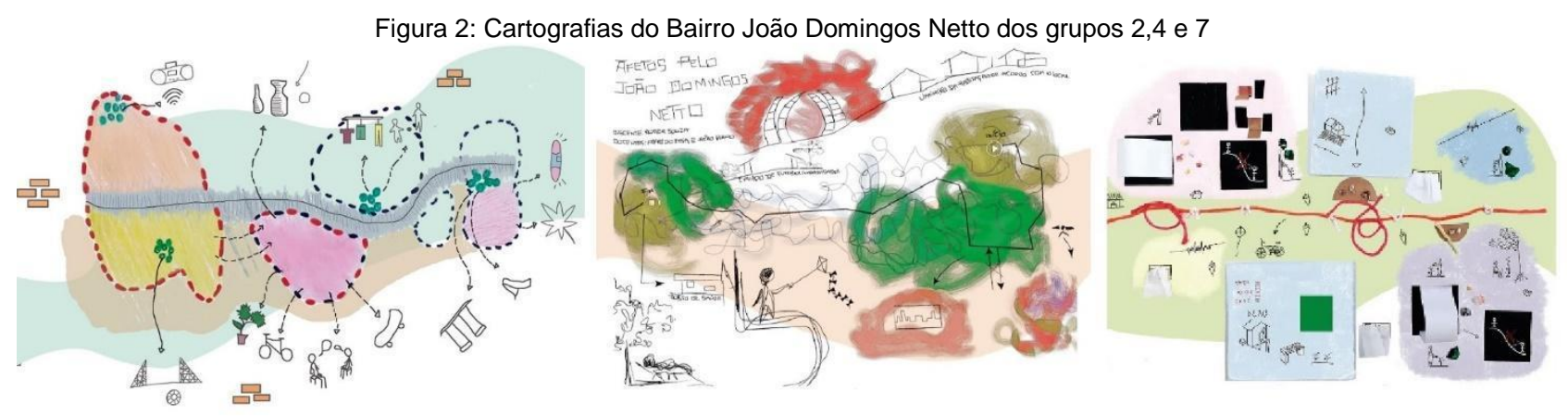



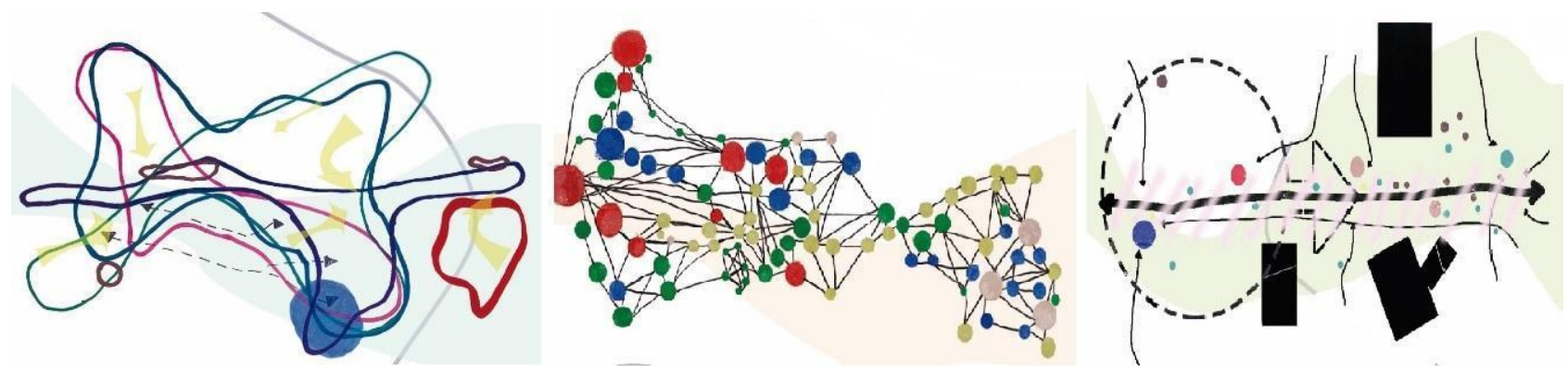

Fonte: Arquivo do Grupo de Pesquisa "Projeto, Arquitetura e Cidade"

A apreensão do atravessamento de forças e afetos entre os corpos e objetos simultaneamente com o conhecimento das características geomorfológicas (Figura 3) através da elaboração de cartografias possibilitou escolherem os terrenos do projeto de centro comunitário a ser desenvolvido.

Figura 3: Mapa Geomorfológico do Bairro João Domingos Netto dos grupos 2 e 4.
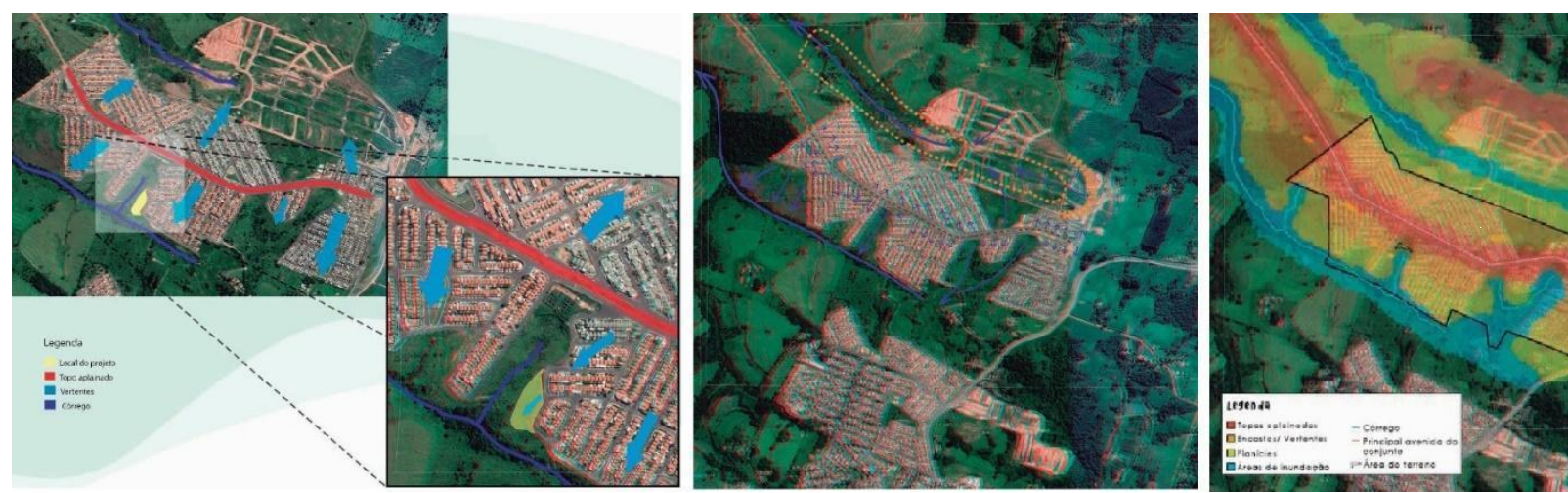

Fonte: Arquivo do Grupo de Pesquisa "Projeto, Arquitetura e Cidade”, 2019.

Outras derivas realizadas nos locais selecionados e seu entorno, proporcionaram uma intensa imersão no conteúdo de eventos socioespaciais existentes, deixando os territórios conquistarem seus corpos e, foram expressos graficamente (Figura 4) pelas cartografias das sensações, dos eventos e situações, inclusive com meios naturais presentes.
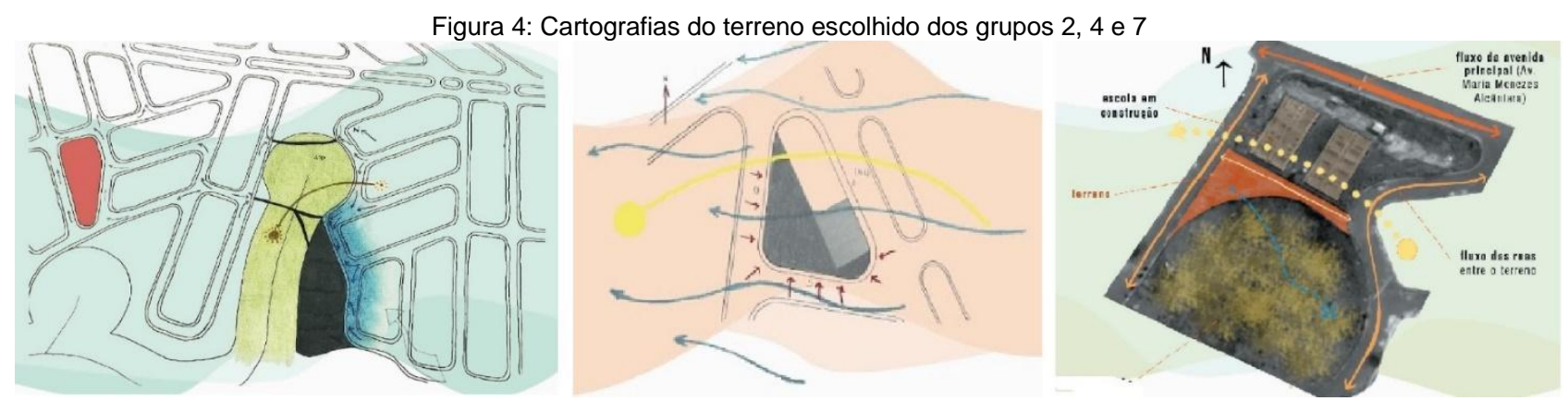

Fonte: Arquivo do Grupo de Pesquisa "Projeto, Arquitetura e Cidade”, 2019.

Em um segundo momento, após a prática cartográfica, os grupos organizaram suas apreensões de outro modo, por diagramas de palavras espacializando os verbos que identificam as atividades reconhecidas, demonstrando a rede de relações e conexões da realidade, o que possibilitou materializar o conteúdo do centro cultural (Figura 5).

$\mathrm{O}$ intuito neste segundo momento foi imergir o aluno em experiências arquitetônicas, relacionando-se com verbos e promessas singulares e não com substantivos (PALLASMAA, 2018). Não se trabalha com 
certezas, agenciam-se incertezas, potencializa-se, não se atribui funções, ativam-se práticas espaciais, verbos.

Figura 5: Diagramas dos verbos da atividade do centro comunitário dos grupos 2, 4 e 7.
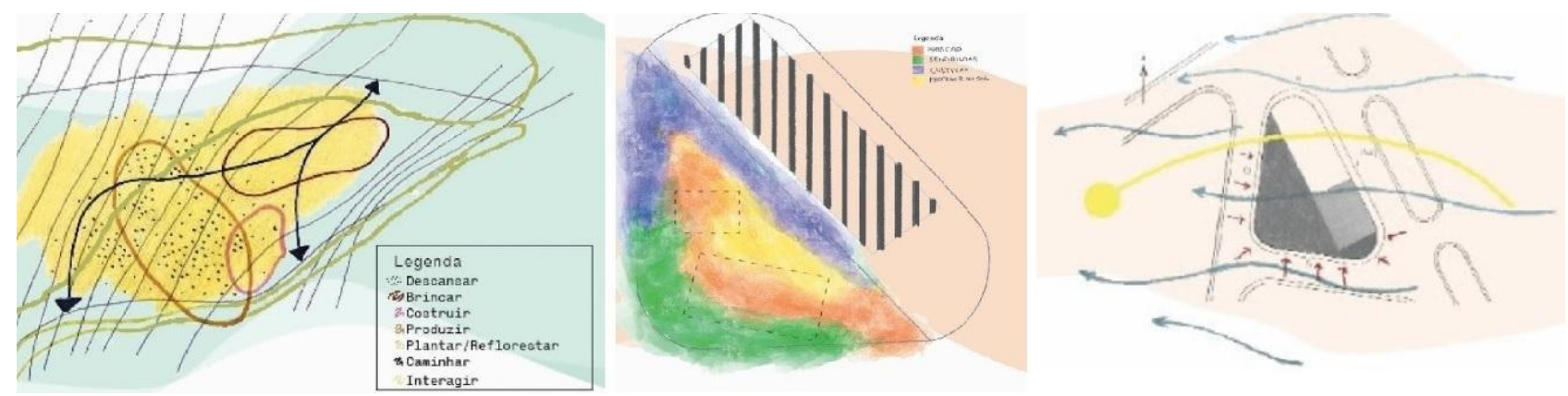

Fonte: Arquivo do Grupo de Pesquisa “Projeto, Arquitetura e Cidade”, 2019.

Desse modo, pensou-se em um centro comunitário que não fosse baseado em nenhum outro modelo existente ou ideal, de outro contexto, mas a partir das ativações da ressingularização das práticas existentes, potencializando outras, de acordo com desejos e imaginários construídos colaborativamente com os sujeitos do bairro.

Nesta etapa, cabe também entender, que o procedimento metodológico aplicado concretiza-se através do reconhecimento das práticas existentes, não operando dentro do Zeitgeist, mas sim sobre o Zeitgeist (EISENMAN, 2005). Desse modo, fica claro que as os agenciamentos são composições das relações sociais, geomorfológicas e de desejos imaginários, ao oposto das intenções temporais e de modismos, tão tradicionais.

\section{INTERVENÇÃO}

Nesse procedimento projetual adotado, não existe um encaminhamento linear hierárquico e sequencial; a tessitura das conexões das forças e afetos entre os corpos-sujeito-objeto-território conduzem os diversos momentos do projeto de modo simultâneo. A intervenção é cartografia, que é deriva. que é projeto; são simultâneos, a forma é expressão do conceito (conteúdo mais contexto).

A proposta do grupo dois de E. B. S. S., G. C. G. V, G. M. C. e K. S. A. U (Figura 6), atravessa a cartografia com colagens de linhas e coágulos de forças e afetos para expressar seu constante movimento no espaço. Dessa forma, a intervenção transborda os espaços das áreas de proteção ambiental com os do centro comunitário, estabelecendo fortes conexões potencializando ativações de práticas existentes com proposições de educação ambiental , respeitando as características geomorfológicas e suas ações naturais.

Por outro lado, o grupo quatro de M. V. B., U. L. D. F., F. G. A. C. e R. S. S.(Figura 7), em um terreno adjacente ao Centro de Saúde concebem um coágulo de forças e afetos com linhas abertas que transbordam para o bairro e vice-versa. Aqui, mesmo com a dificuldade topográfica encontrada, ao perceber que o nível de implantação estava aproximadamente a dois metros abaixo da edificação existente, o grupo se utilizou das linhas em rampas, que permitiram a permeabilidade e esse transbordamento. Nesse contexto, espaços de usos indeterminados penetram o edifício e se abrem ao entorno, proporcionando espaços de diversos caráteres de intimidade e coletividade.

Figura 6: Dos diagramas conceito para o projeto do centro comunitário do grupo 2.
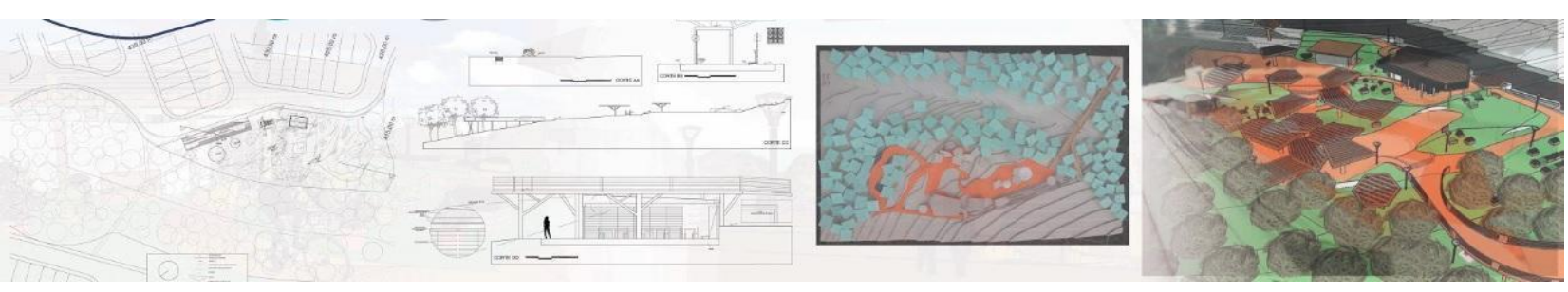

Fonte: Arquivo do Grupo de Pesquisa "Projeto, Arquitetura e Cidade", 2019. 
Figura 7: Dos diagramas conceito para o projeto do centro comunitário do grupo 4
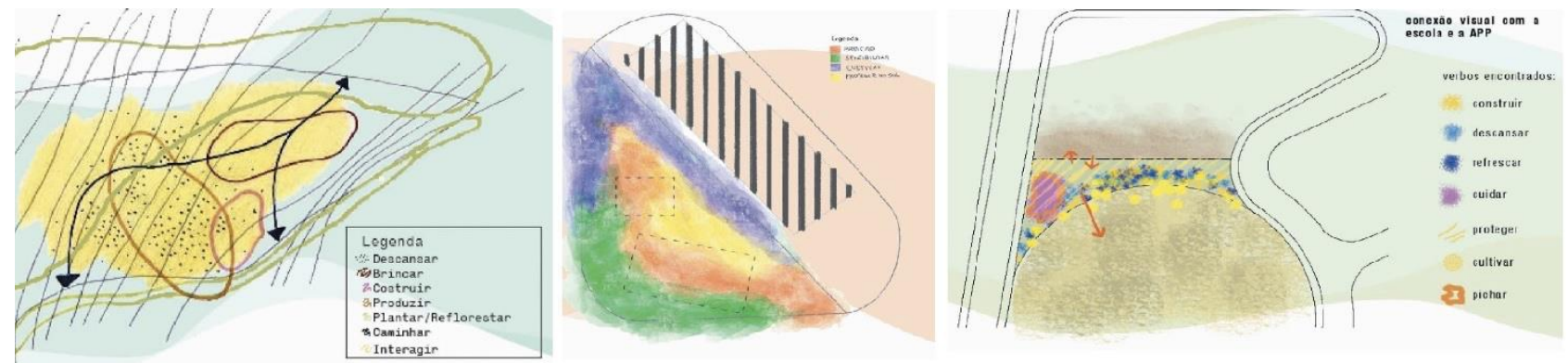

Fonte: Arquivo do Grupo de Pesquisa "Projeto, Arquitetura e Cidade", 2019.

Da mesma forma, em um terreno residual próximo a uma área de proteção ambiental, o grupo sete de G. B. P., J. R. Z., K. P. M. S. e L. L. S.(Figura 8), a cartografia de forças e afetos conduz a intervenção. No lugar adotado, há um estrangulamento peculiar entre a linha delimitadora da área de proteção permanente, gradeada e o acesso oposto do terreno da área institucional, também protegida por grades. Mesmo assim, o grupo conseguiu absorver as fortes linhas limites, de barreira, transpondo as guias em pontos visuais aleatórias ao percurso linear inevitável. A tecitura das linhas e coágulos simultâneos às características do solo e a ações naturais e intervenções promove um caminho para ativar as sensações humanas, interligando espaços setorizados com indeterminação e de caráter individual e coletivo. Potencializa as forças e afetos ativando os múltiplos territórios expressos na forma arquitetônica.

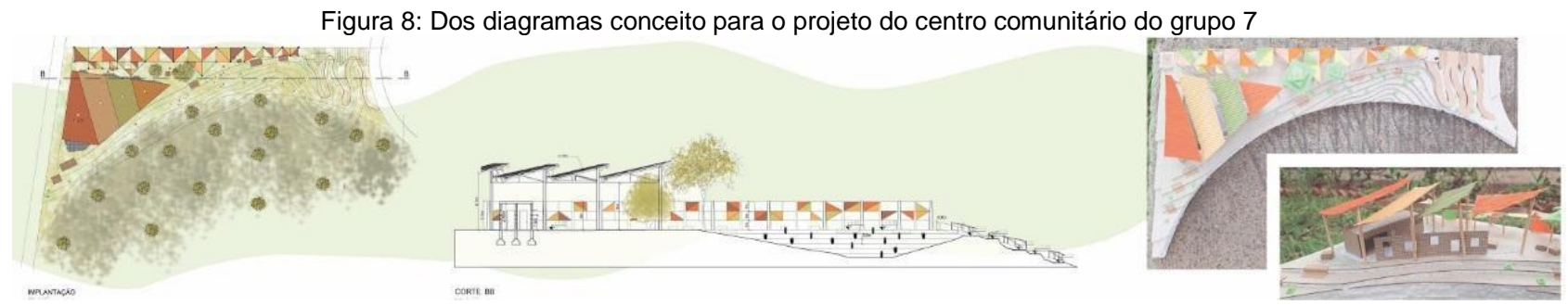

Fonte: Arquivo do Grupo de Pesquisa "Projeto, Arquitetura e Cidade", 2019.

Nas demais intervenções perceberam-se a intencionalidade dos grupos em se utilizar do procedimento metodológico na apreensão e cognição do espaço trabalhado, como espaço existencial, observando a intensidade permanente das cartografias, intervenções e condicionantes da geomorfologia no processo da ação projetual.

\section{CONCLUSÃO}

O estranhamento inicial na relação professores e alunos mediados pelo procedimento metodológico adotado foram desaparecendo ao longo do processo. A expectativa dos alunos de terem uma fórmula, um protocolo que encaminhasse para resolver um problema, ou a um projeto ideal dificultou o desenvolvimento inicial das disciplinas.

No entanto, os alunos foram percebendo que não basta a busca por uma forma arquitetônica exuberante e ou espetacular, é preciso estar no meio das redes de conexões socioespaciais, reconhecer os territórios heterogêneos habitados, seus conflitos, suas diversidades, multiplicidades e singularidades.

Dessa forma, a elaboração da forma arquitetônica é simultânea com a apreensão das práticas espaciais e construção do conceito do projeto, que expressa a cidade subjetiva das forças e os afetos entre corpos. Nesse sentido as cartografias realizadas coincidem com as formas elaboradas.

Assim como, apreenderam o valor transitório da intervenção projetual, ao constatar a transformação constante dos territórios, a realidade em movimento, retratando o valor da incerteza: não solucionam um problema, o projeto precisa conter espaços indeterminados e flexíveis, a serem determinado pelos sujeitos do espaço e poderem acompanhar o movimento das mudanças constantes dos territórios atravessados pelos afetos. 
Do mesmo modo, as intervenções afirmam um paradoxo procurando manter simultaneamente a ativação das práticas existentes, mas ressingularizadas e potencializar o atraso da utilização de analogias tipológicas de obras referenciais, para depois da definição do conceito do projeto, ao expressar a forma da cidade subjetiva mais próxima da cidade real.

\section{REFERÊNCIAS}

CARERI, F. Walkscapes: o caminhar como prática estética. São Paulo: ed. GG, 2013

CERTEAU, M, A invenção do cotidiano: Artes de fazer. 3 ed. Petrópolis: Vozes, 1998

DEBORD, G. Teoria da deriva. Revista IS n 2, dez. 1958 In: JACQUES, P.O. (Org). Apologia da deriva. Rio de Janeiro: Casa da Palavra, 3d

DELEUZE, G. \& GUATTARI, F. L'Anti-Oedipe. Paris: Minuit, 1972. Ed. Port.: O Anti- Édipo. Tr. Varela, J.M. e Carrilho, M.M. Lisboa: Assírio e Alvim, edição s/d [1972].

. Mil platôs. Vol. 1. São Paulo: Editora 34, 2019

EISENMAN, P. in ZAERA-POLO, Alejandro. Arquitetura em diálogo. São Paulo: Cosac Naify, 2015.

JACQUES, P. B. Apologia da deriva. Escritos situacionistas sobre a cidade. Rio de Janeiro: Casa da Palavra, 2003, p.13-39

LIMA, Z. O projeto como prática crítica: repensar o possível e o presente. Pós. Revista do Programa de Pós-Graduação em Arquitetura e Urbanismo da FAUUSP, v. 11, p. 90-101, 20 jun. 2002.

GUIZZO, I. Reativar territórios: o corpo e o afeto na questão do projeto participativo.Belo Horizonte: Quintal, 2019.

NORBERG-SCHULZ, C. Genius Loci: Towards a Phenomenology of Architecture. New York: Rizzoli, 1980.

PALLASMAA, J. Essências. São Paulo: Gustavo Gili, 2018

TSCHUMI, T. Concepto, Contexto, Contenido. In Arquine, Revista Internacional de Arquitectura y Diseño. № 34, 2005

ZUMTHOR P. Atmosferas: entorno arquitectônicos - as coisas que me rodeiam. Barcelona: Gustavo Gili, 2009

NOTA DO EDITOR (*): O conteúdo do artigo e as imagens nele publicadas são de responsabilidade do(s) autor(es). 